\title{
Developmental Origins of Disease Paradigm: A Mechanistic and Evolutionary Perspective
}

\author{
PETER D. GLUCKMAN AND MARK A. HANSON \\ Liggins Institute [P.D.G.], University of Auckland and National Research Centre for Growth and \\ Development, Private Bag 92019, Auckland, New Zealand; and Centre for Developmental Origins of \\ Health and Disease [M.A.H.], University of Southampton, Princess Anne Hospital Level F (887), \\ Southampton S016 5YA, United Kingdom
}

\begin{abstract}
ABST
Fetal growth is determined by the interaction between the
environment and the fetal genome. The fetal environment, in
turn, is determined by the maternal environment and by maternal
and placental physiology. There is evidence that the interaction
between the fetal environment and genome can determine the
risk of postnatal disease, as well as the individual's capacity to
cope with the postnatal environment. Furthermore, the role of
various forms of maternal constraint of fetal growth in determin-
ing the persistence of these responses is reviewed. A limited
number of biologic processes can contribute to the mechanistic
basis of these phenomena. In addition to immediate homeostatic
\end{abstract}
The developing embryo and fetus are highly sensitive to their environments, and in late gestation, many fetal homeostatic responses can be readily discerned. In general, the fetus has three types of responses to an adverse environment: it can accelerate its maturation (e.g. by elevating glucocorticoid levels), conserve nutrients (by reducing growth and activity), or terminate the pregnancy altogether by spontaneous abortion or premature delivery. The third option is better understood in evolutionary terms, because a subsequent fetus can be conceived, but death of the mother results in loss of her genome. Hence, the fetus is a less than "perfect parasite," and in the hierarchy of demand, most circumstances will favor the mother.

Defining the fetal environment is complex. In the immediate sense, it is defined by the intrauterine environment, which in turn is affected by maternal health and the maternal environ-

Received January 5, 2004; accepted May 17, 2004.

Correspondence: Peter D. Gluckman, MBChB, MMedSc, DSc, Liggins Institute, University of Auckland and National Research Centre for Growth and Development; 2-6 Park Avenue, Grafton, Private Bag 92019, Auckland, New Zealand; e-mail: pd.gluckman@auckland.ac.nz

M.A.H. is supported by the British Heart Foundation.

DOI: 10.1203/01.PDR.0000135998.08025.FB responses, the developing organism may make predictive adaptive responses of no immediate advantage but with long-term consequences. An evolutionary perspective is provided, as well as a review of possible biologic processes. The "developmental origins of disease" paradigm is a reflection of the persistence of such mechanisms in humans who now live in very different environments from those within which they evolved. The developmental origins paradigm and its underlying mechanistic and evolutionary basis have major implications for addressing the increasing burden of metabolic and cardiovascular disease.

(Pediatr Res 56: 311-317, 2004) ment, as well as by the function of the uteroplacental unit. Fetal nutrition and maternal nutrition are not identical. Fetal nutrition lies at the end of a long supply line extending from the maternal macroenvironment, through the maternal gastrointestinal and metabolic physiology, and the uteroplacental unit (1). Thus, the fetal nutritional environment does not simply reflect the gross external environment, although it is clearly affected by it.

Nutrition, including both nutrient and oxygen delivery, is just one set of factors that affect fetal growth and maturation. Other factors to consider include maternal effects, genetic influences, and age at pregnancy. One feature, in particular, is the phenomenon of maternal constraint, whereby the growth of the fetus is limited so that it cannot outgrow the mother's reproductive tract and her capacity for vaginal delivery. The mechanisms underlying maternal constraint are poorly understood but may include limitations in uterine vasculature and placental function $(2,3)$. In addition, parentally imprinted genes may exert different effects. For example, the maternally silenced, paternally expressed growth factor IGF-2 drives fetal growth (4), and, at least in mice, the clearance receptor IGF-2R is expressed by the maternal allele, particularly in the placenta (5). There is also evidence for a paternally imprinted transcript 
of IGF-2 in the placenta (6), and in humans, bi-allelic expression of the IGF-2 gene results in fetal overgrowth (BeckwithWeidemann syndrome) (7).

Physiologic limitations of fetal growth, which may or may not reflect similar mechanisms, are greater in primiparous pregnancies and lead to smaller birth size; this may relate to a lesser capacity for vasodilation in the primiparous uterine vasculature $(8,9)$. This is important because the percentage of pregnancies that are primiparous is rising dramatically, particularly in some developing societies, such as China, where family size is restricted, and in industrialized nations, where changes in lifestyle, health, and working patterns result in smaller families.

Young maternal age can also affect fetal growth as young mothers give birth to smaller fetuses (10). Although this is compounded by maternal size and parity, the most likely explanation is that the younger mother has priority for utilizing nutrients for her own anabolism and growth. In evolutionary terms, there may be a survival advantage in a young mother's limiting her resource commitment to reproduction until she is fully grown herself (an example of supply-driven constraint). Much less is known about the older mother, but this is clearly an area that merits priority in research, as later pregnancy is an increasing aspect of many developed societies. Twinning also reduces fetal size but does so by competition on the demand side because the fetuses compete for a constrained supply of nutrients. This suggests that more than one mechanism may be involved in maternal constraint.

Fetal origins hypothesis and the developmental origins of disease paradigm. In 1988, the first reports of relationships between measures of birth size and long-term disease risk appeared (11-13). These retrospective studies, conducted initially on British cohorts, related rates of mortality from coronary heart disease to birth size. An inverse relationship was found, and similar relationships were subsequently discovered for other components of the metabolic syndrome (Syndrome $\mathrm{X}$ ), including hypertension, stroke, insulin resistance, type 2 diabetes, and dyslipidemia. These studies led to the so-called "fetal origins" hypothesis, in which it was suggested that events in utero, which reduced fetal growth, permanently altered the structure and physiology of the offspring such that the risk of heart disease and diabetes in later life was increased. Subsequently, interactions were reported between the pre- and postnatal environment, such that those who had the most adverse intrauterine environment (evident by reduced birth size) and gained weight fastest after birth were shown to be at greatest risk (14). The initial model was refined and named "the thrifty phenotype hypothesis" (15): its name contrasted with the thrifty genotype hypothesis (16). The latter postulated that modern populations evolved by evolutionary selection for characteristics that conferred an advantage in a deprived environment but that put them at risk for type 2 diabetes and related disorders in an enriched environment. If this hypothesis is correct, then the origins of such disease should now be primarily genetic and its incidence determined by heritability and environment. The thrifty phenotype hypothesis proposed by Barker and Hales (15) instead argues that the rapidly changing incidence of disease cannot be explained in terms of a genetic component. They proposed that the fetus responds to an adverse environment by reducing growth and making developmental adaptations that are appropriate to an anticipated deprived (in nutritional terms) postnatal environment. Should the actual postnatal environment be adequate, these same adaptations would increase disease risk. The word "programming," first introduced by Lucas (17) in relationship to the longer term outcomes of various infant feeds, has been adopted to describe the unknown linkages between fetal life and long-term consequences.

Controversy. Over the next decade, a large number of epidemiologic studies were performed in different populations, confirming the relationship between birth size and long-term disease risk (for review, see Ref. 18). The concept was reinforced by the observation that genotypic polymorphisms that influence the strength of the relationship exist (19), making it clear that these polymorphisms arise as a result of geneenvironment interactions. However, because of the paucity of information that could be used to characterize individuals in retrospective studies, few studies focused on disease outcomes, and most concentrated on surrogate measures, such as blood pressure or fasting insulin. Others relied on recalled birth weights, with the obvious limitations (20). When the outcomes were those of disease, the relationships were unequivocal; when surrogates were used, the relationships tended to be weaker. This important point was missed in a recent critical review of the available epidemiologic data (21), which also ignored the compelling prospective clinical data. For example, there are reports of differences in the metabolic biology of children and adults who were born small compared with infants who were born of normal size, suggesting early development of insulin resistance $(22,23)$. Similarly, the available twin data had been misinterpreted, as is discussed subsequently, and there was essentially no consideration of the extensive literature from experimental animals.

The most frequent misunderstanding in this field has been the role of birth size. It is our view that this has led to much misinformed criticism of the general paradigm. Birth size is simply a crude surrogate reflecting the interactions between the fetal environment and the fetal genome. There are many adverse events that may have an impact on the fetus and have long-term effects yet have no effect on birth size. For example, in the Dutch winter famine, women who ate $<800$ calories a day in the first trimester gave birth to normal-sized infants who later became obese $(24,25)$. Recent studies demonstrate that patterns of human fetal growth are influenced by variations within the normal range of maternal dietary intakes (26). A range of animal experiments in which programming has been induced in offspring by prenatal nutritional or endocrine manipulation have also demonstrated that the effects can be produced in the absence of a change in birth weight (27-31). It is clear that programming is not a process confined to the extremes in fetal growth but rather one that accompanies the adaptations that every fetus makes to its environment, including subtle variations in growth. This explains the continuous relationship between birth size and measures of later disease outcome. Although the relationship between birth size and outcome has been fortuitous in the recognition of a develop- 
mental origin to adult disease, it is not part of the causal pathway. One example may serve to illustrate this. In twin studies, the lighter twin has been shown to be at greater risk of developing insulin resistance and diabetes, perhaps reflecting differing substrate availability between the twin pair (32). More recently, other studies have shown that compared with singletons, both twins, independent of their size, are insulin resistant because both have developed within a supply-limited environment (33).

\section{Multiple Pathways to Induction}

Animal models have provided the most direct proof of the principle, but in doing so they have generated another important concept; namely, that the consequences of programming have been so critical to survival of a wide range of species that evolution has ensured that multiple mechanisms exist to induce it. Programming has been demonstrated in pigs, sheep, mice, and rats (for review, see Ref. 29). Typically, programming has been induced by prenatal undernutrition (in total caloric or protein content of the diet), by unbalanced nutrition (e.g. feeding a high-lard diet to the mother), by impairing uteroplacental perfusion, or by maternal exposure to synthetic glucocorticoids. However, the fetus need not be manipulated for the same relationships between birth size and cardiovascular and metabolic outcome to be observed (34). The environmental cue can occur early or late in pregnancy and still program the fetus. Indeed, in the rodent, there are data extending to the preimplantation phase (35). For this reason, the term "fetal origins" has now been replaced by "developmental origins." Although each experimental approach has its limitations, all induce offspring with tendencies toward insulin resistance, high blood pressure/vascular dysfunction, more rapid weight gain, and, where measured, an increased adiposity. Clearly, multiple mechanisms must be involved if diverse cues at different stages of development give rise to similar phenotypes.

Mechanistic explanations. Fundamentally, the mechanisms underlying programming must operate at three levels, and there are experimental data to support each; they are epigenetic change, changes in cell-cycle regulation, and changes in cellular or tissue differentiation. One caveat on the interpretation of experimental studies is to distinguish between experimental manipulations that may induce developmental disruption (i.e. are teratogenic) from those that represent environmental influences of adaptive significance. Epigenetic change involves a permanent, environmentally induced change in gene expression; this may be via a change in DNA methylation or histone modification. The former utilizes one-carbon groups derived in part from dietary glycine. Folate and vitamin B12 are essential co-factors for this metabolic pathway. These epigenetic changes are the basis for imprinting processes that determine the expression of maternal or paternal alleles in early development. However, the extent of such processes extends beyond imprinting, and this is an actively researched area. In the agouti mouse, providing the dam with dietary supplementation that contains folate at conception changes the degree of imprinting on the agouti gene in her offspring (36). Both folate and glycine supplementation reverse the effect of a low-protein diet in pregnancy on the blood pressure and vascular function of the offspring $(37,38)$. In sheep embryo culture, altered in vitro conditions lead to changes in gene expression of imprinted genes through fetal life (39), but epigenetic processes need not be restricted to imprinted genes-changes in the use of alternative promoter regions in the glucocorticoid receptor gene have been induced in the rat pup by manipulating mother-offspring behavioral interactions, and such effects have long-term consequences (40).

We suspect that epigenetic change will turn out to be a major mechanism underlying programming, with implications for subsequent generations. For instance, it is now clear that not all epigenetic change is lost at meiosis. In the agouti mouse, transgenerational effects are reported (36). In the Dutch winter famine, women who were exposed to famine while in the womb later had grandchildren who were born with reduced birth size (41). There are also preliminary reports that such transgenerational effects can occur in the F2 generation of rats that are exposed to a low-protein diet in pregnancy $(42,43)$. Whether these effects occur as a result of germline transmission or via perturbed maternal vascular adaptations to pregnancy is not known (44). Another explanation concerns the size of the reproductive tract. The uterus develops largely in the first trimester, and it is reported that uterine size is reduced in girls who are born small; hence, they may exert greater maternal constraint when they in turn become pregnant (45). Transgenerational effects are well described in the comparative literature, where they are generally termed "maternal effects." Thus, there remains a possibility that transgenerational epigenetic change may play a role in clustering or family linkage effects for diseases such as type 2 diabetes.

There are reports suggesting altered cell proliferation or apoptosis in programmed animals. For example, there is increased $\beta$-cell apoptosis in the pancreatic islets of offspring of protein-restricted mothers (46). Perhaps similar mechanisms might explain the reduced neuronal count found in some regions of the brain after experimental intrauterine growth retardation induced by reduced uteroplacental perfusion (47). A shortened telomere length is reported in the kidney of rat pups whose dams were fed a low-protein diet in pregnancy, suggesting accelerated cell cycling or aging-related processes (48).

Altered tissue differentiation is also well described in developmental programming. Reduced capillary density is reported in several organs after maternal malnutrition, and this might be linked to the increased evidence of endothelial dysfunction in programmed animals (for review, see Ref. 49) and indeed in the pathologic consequences in humans (50). Reduced numbers of nephrons are formed if there is an adverse intrauterine environment during a critical developmental window (51), and this is clinically relevant as it has been reported that individuals with essential hypertension have fewer nephron numbers (5254). Skeletal muscle fiber development also seems to be restricted (55), and there is increasing evidence for altered adipose tissue development (see below). Permanent functional abnormalities as a result of altered enzyme expression patterns are seen in the livers of the offspring of low-protein-fed rat dams, and these lead to a relative increase in glucose produc- 
tion at the expense of glucose storage (56). All of these tissue-specific effects can be viewed as adaptations that restrict energy consumption, whether in terms of nutrient delivery to tissues (reduced capillarity), reduced size of the most metabolically active tissues (e.g. nephrons), or alteration in the balance between energy-consuming and energy-storing tissues (skeletal muscle versus fat).

Multiple effector mechanisms have been described for the induction of these processes, and they have been reviewed recently (57-59). They include altered sensitivity in the hypothalamic-pituitary adrenal axis and a multitude of defects in insulin sensitivity and cardiovascular control (18). Recently, behavioral changes that include hyperphagia and lethargy in the offspring of rats undernourished in pregnancy have been shown experimentally (59) - perhaps these observations are relevant to origins of the human metabolic syndrome. All of these effects are magnified by rapid dietary-induced growth $(14,60)$, particularly in the postinfancy period.

Developmental programming as an example of a predictive adaptive response. The ease with which such effects can be induced experimentally suggests that there have been powerful underlying evolutionary pressures to retain them. It has been convention in clinical medicine to think of responses to the environment as being only of immediate advantage - that is, either homeostatic if the challenge is short lasting or homeorhetic if it is more prolonged (61). The programming paradigm raises the possibility of an additional kind of environmental response- one in which the benefit need not be immediate but in which the response is made in expectation of a future environment. We have termed such responses predictive adaptive responses (62).

A good example of a predictive adaptive response is seen in the meadow vole, which gives birth to pups with different coat thicknesses depending on the photoperiod to which the mother is exposed, i.e. whether the pups are born in the autumn or the spring and, thus, whether cold or warm temperatures are expected in coming months (63). At the time this trajectory is chosen, the pups are in utero at a constant temperature; the response is driven by the maternal melatonin rhythm (lengthening or shortening with the changing photoperiod) before birth (64). Even though the short-term postnatal environment of the nest is similar in both situations, coat thickness is set before birth for the environment predicted weeks later, when the pups leave the nest. Therefore, the vole has evolved with a strategy to predict its future environment and to make permanent adaptive responses in anticipation of that future.

Thus, a predictive adaptive response may be appropriate or inappropriate. If the prediction is correct (i.e. if the postnatal environment is as predicted during prenatal development), then it is appropriate; if the prediction turns out to be incorrect, then the predictive adaptive response is inappropriate. Such a distinction, of course, can be made only retrospectively.

We propose that there are many physiologic systems in which predictive adaptive responses operate and that the developmental origins paradigm is but one example of such a response, albeit one that can lead to disease when the prediction is inappropriate. In essence, any aspect of developmental plasticity that can be irreversibly affected by the environment can be considered to be a predictive adaptive response if it confers a long-term survival advantage when the predicted and actual future environments match. This is demonstrated in the development of human sweat glands: the number of active sweat glands is set in the first year of life by the ambient temperature in humans (reviewed in Ref. 18). If a person who is born in a cold climate lives in hot climate, then he or she is more at risk of heat stress - the early prediction about future environment was incorrect, and the predictive adaptive response becomes inappropriate.

Evolutionary significance of predictive adaptive responses. Elsewhere we have pointed out that evolutionary processes (including speciation) must operate in the context of a permanent or very prolonged change in the environment. However, all species must also cope with transient changes in environment if they are to survive (62). In generalist species such as Homo sapiens, genetic variation induced by drift and mutation needs to be maintained for optimal success in a wide range of environments. If the range of phenotypes expressed by a given genotype is such that in the face of a given transient environmental change, a number of genotypes will be unable to survive, then it is easy to envisage that alternating environmental shifts acting over several generations could lead to species extinction. Predictive adaptive responses, however, provide a process by which individuals adapt to their future postnatal environment by restricting their range of possible phenotypes to a narrower spectrum, without changing the genotype. If the adaptive change is matched to the predicted environment, then a broader range of genotypes will survive the transient change. Maximal genotypic variation in the species will be preserved, upon which evolutionary selection can act over a much longer time scale.

So predictive adaptive responses allow a species to survive to reproduce in a compromised environment. This concept was heralded in the thrifty phenotype hypothesis, by which the fetus makes adjustments in the expectation of a future-deprived environment, on the basis of nutritional and hormonal cues from the mother. It sacrifices muscle mass and energy utilization for growth by reducing vascularization and developing relative insulin resistance and may alter its maturational tempo so as to reproduce. In evolutionary terms, survival to reproduce is the key driver because selection is stronger up to peak reproduction and then declines $(65,66)$. Thus, selection will not act to select against deleterious effects that occur in or after middle age. The concept of predictive adaptive responses extends the thrifty phenotype idea because, by including processes such as those of maternal constraint, it shows how such developmental adaptive responses operate in all pregnancies.

Origins of human disease. Let us now put this into the human perspective. For reasons discussed further below, we have evolved to be particularly sensitive to the nutritional and perhaps stress-inducing components of the environment. The maternal environment is transmitted to the fetus by means of nutritional and endocrine signals, and it makes a set of adaptive responses in expectation of the postnatal environment that it perceives to be extant on the basis of these maternal signals, but the perception may be wrong. At one extreme, the mother may be in poor health or the placenta dysfunctional, either of 
which limits nutrient transfer to the fetus, making nutrition unbalanced or altering fetal hormonal levels. Such effects clearly occur in the case of preeclampsia or gestational diabetes.

However, we have emphasized that the fetal environment is normally controlled by such maternal and placental factors, that this is the basis for the maternal constraint that limits the role played by the offspring's genome on growth before birth (3). Thus, both maternal constraint and pathophysiologic processes will initiate adaptive responses by the fetus (62). Postnatally, there will be minimal consequences if the environment matches the prediction, but if there is severe disease or constraint or if the postnatal environment changes rapidly, by, for example, migration to a nutritionally rich habitat, then the predictive response will turn out to be inappropriate.

As hominids evolved in a pre-agricultural era where the postnatal nutritional environment was limiting and unpredictable, the risk of an inappropriate prediction producing disease as a result of maternal constraint would have been minimal. Moreover, life expectancy was shorter during this era, diminishing the likelihood for disease in middle age. Indeed, we propose that maternal constraint evolved, or was selected by evolution, because it conferred an additional advantage to that of matching fetal and maternal size. By always limiting nutrient supply to the fetus, constraint ensured that the evolving hominid set the offspring's phenotype toward the default position of predicting an uncertain postnatal nutritional environment. Even now, the role of maternal constraint is evident by the relationship between maternal and infant birth weights, whereas the relationship with paternal birth weight is weak (67). Recently, Stettler et al. (68) and Morton (69) showed that first-born children have an increased risk of developing obesity than their subsequent siblings, demonstrating the influence of parity as an aspect of the constraint that induces predictive adaptive responses. Thus, humans have evolved with a tendency toward omental fat deposition and with characteristics that were of no consequence to the hunter-gatherer with uneven food supply but are now of great consequence to modern man. With today's high, constant nutrition, the hidden effects of this survival phenotype are frequently manifest as a risk of disease. It will be obvious from this model that the greater the adversity of the fetal environment or the degree of constraint, the greater the risk of a mismatch between the modern prenatal, constrained environment and the modern postnatal, energy-rich environment.

This can be exemplified further by reference to a Southern Indian population versus a European population $(70,71)$. In rural India, women are small because of generations of relative nutritional deprivation and give birth to small infants because of maternal constraint. Although small at birth, these infants, nevertheless, have relative truncal obesity, an adaptation that gives them energy reserves for early independent life, and relatively less skeletal muscle, which limits glucose consumption by this tissue. Complicating this issue is that although maternal size constraint still operates, the postnatal energy environment has improved rapidly in parts of India, especially for those who have migrated to the cities. The predictive adaptive responses for those who are born small (as a result of inadequate nutrition and/or constraint) are now inappropriate, explaining the rapidly rising incidence of diabetes. Similar observations are reported with respect to the prevalence of diabetes in migrant populations as migration is usually a rapid shift to a richer, nutritional environment (72).

Predictive adaptive responses operate at all levels of prenatal nutrition. We summarize this model in Fig. 1. If the fetus predicts a good postnatal environment, then it will evolve a physiology that is appropriate to a given range of postnatal environments where disease is of lower risk. If the fetus predicts a deprived postnatal environment, then it will develop a physiology that is more appropriate for a lower range of nutrition. What this means is that there is a limit of nutritional range above which "life style" disease is likely to become manifest. This upper limit differs depending on the fetal prediction of its postnatal environment. The prenatally constrained fetus - as a result of physiologic maternal effects including constraint or by maternal-placental disease - will make predictive adaptive responses appropriate for a lower postnatal nutritional range and have a lower nutritional threshold for disease risk.

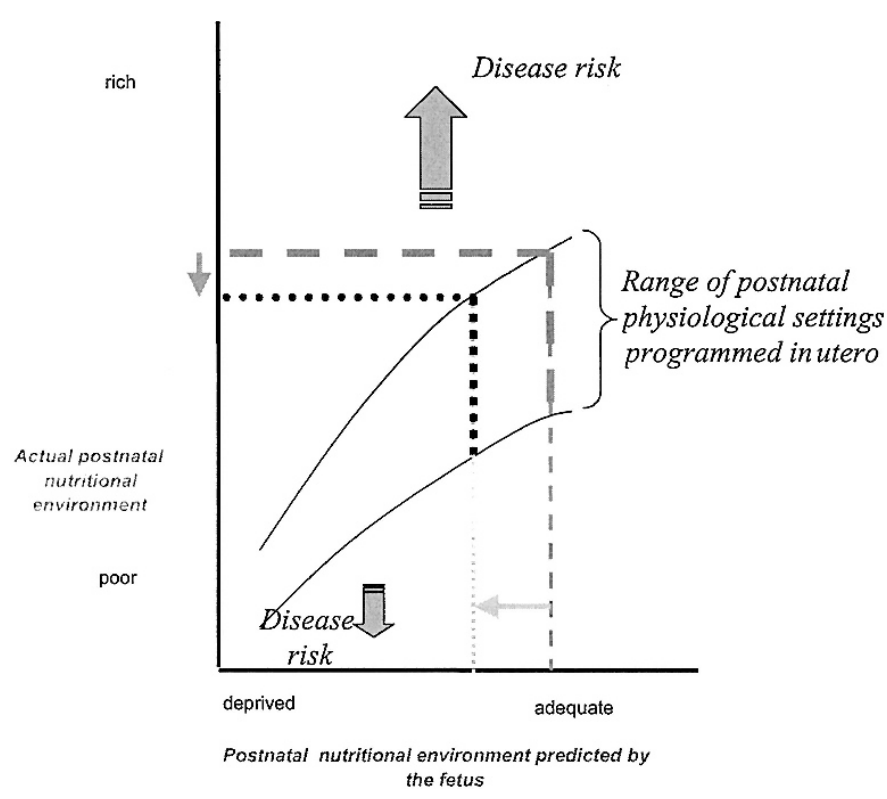

Figure 1. A model that demonstrates the effect of predictive adaptive responses acting to program the limits of physiologic adaptations. The abscissa represents the environment that the fetus anticipates postnatally, judged from the nutritional and related signals that it receives from the mother through the placenta. The ordinate represents the actual postnatal nutritional environment in adulthood. The band created between the two curves represents the range of postnatal environments for which the fetus has set its postnatal physiology by the processes of predictive adaptive responses. Provided the postnatal environment matches that range, disease risk is low, but if the postnatal environment lies outside this band, then disease risk is increased. The dashed vertical line represents the setting of an optimally growing fetus, which establishes an upper limit (horizontal dashed line) of postnatal nutrition associated with health. The dotted line represents the same fetus exposed while in utero to increased maternal constraint or significant maternal/placental disease. The fetus perceives the more restricted environment and predicts a poorer postnatal environment. The result is a downward adjustment in the postnatal physiologic settings. This shifts the upper limit of the postnatal nutritional range associated with health downward, so the risk of diseases is correspondingly increased. 
Antenatal origins of obesity. There is increasing evidence that truncal obesity is itself prenatally programmed as part of the survival phenotype (71). Both prenatally nutritionally deprived sheep (73) and rats (58) develop postnatal truncal obesity. In the rodent studies, effects on appetite (58), food preference, and exercise willingness (59) are described. Clinical studies have shown inverse relationships between birth size or maternal weight gain or nutritional status and truncal obesity in adolescence (74). Children who are born small have disproportionately high leptin levels, suggesting leptin resistance (75). Thus, the compounding factor of postnatal fat deposition may be an inherent part of prenatal programming processes.

The model also explains another paradox exemplified in India: the rising incidence of juvenile-onset type 2 diabetes in children of higher birth weight (76). These children were born to mothers who themselves had been significantly constrained in the course of their own intrauterine development. While in the womb, these female fetuses induced predictive adaptive responses favoring insulin resistance. Years later, when they become pregnant, this programming will be exacerbated by placental lactogen-induced insulin resistance. Although such insulin resistance is a normal adaptation in all pregnancies, in the presence of a degree of significant basal insulin resistance induced in utero by these predictive mechanisms, the placental effect will be amplified and lead to greater glucose transfer to the fetus and, through fetal insulin release, to increased adipogenesis (see Ref. 77 and references therein). Thus, the combination of maternal constraint and high glucose transfer creates a fetus who is born at relatively low absolute weight (although perhaps relatively high for the population) but with an increased fat mass. This combination of factors creates a greater risk of diabetes. A parallel scenario may explain the rising incidence of gestational diabetes in recent decades.

Implications of the developmental paradigm. This model changes perspectives on how to intervene in the "life-style" disease epidemic. It shows that lifestyle interventions alone may be only partially effective in that those who are most affected by inappropriate predictive adaptive responses may be difficult to manage with life-style interventions in adulthood. The model suggests that improving maternal and fetal health will allow humans to cope better with current postnatal nutritional conditions - conditions that we did not evolve to inhabit.

If epigenetic change is the core process underlying such programming, then priority should be given to understanding what epigenetic changes occur, when they occur, the key nutrients involved, and whether there are windows of opportunity during which the effects can be reversed. For some changes, such as reduced nephron number, only a preventative approach can at present be considered. As alluded to above, there is increasing focus on the periconceptual period being the critical period when programming cues are most effective. If that is the case, then the focus will have to be on the health of women before pregnancy and their nutritional status at conception and early pregnancy. There are data pointing to the role of both micronutrient and macronutrient balance (78-80), but the sad reality is that in 2004 , we still do not know the optimal nutritional regimen for women in different stages of their lives and during pregnancy.

Although we have focused on the metabolic axis in this review, similar arguments can be advanced with respect to cardiovascular and skeletal changes appropriate for reproduction and survival. The predictive adaptive response model is also generally applicable to other physiologic systems that may be programmed, for example, thermal and electrolyte homeostasis.

The developmental origins of disease paradigm is clearly important in the evolution of patterns of human disease. Unfortunately, data sets do not yet exist to allow a true assessment of how important, there being only one retrospective calculation on a Finnish population (14). The paradigm does, however, focus our attention on maternal health and is important to our understanding of both human development and evolution.

\section{REFERENCES}

1. Bloomfield FH, Harding JE 1998 Experimental aspects of nutrition and fetal growth. Fetal Maternal Med Rev 10:91-107

2. Gluckman PD, Morel PC, Ambler GR, Breier BH, Blair HT, McCutcheon SN 1992 Elevating maternal insulin-like growth factor-I in mice and rats alters the pattern of fetal growth by removing maternal constraint. J Endocrinol 134:R1-R3

3. Gluckman PD, Liggins GC 1984 The regulation of fetal growth. In: Beard RW, Nathanielsz PW (eds) Fetal Physiology and Medicine. Marcel Dekker, New York, pp $511-558$

4. DeChiara TM, Robertson EJ, Efstratiadis A 1991 Parental imprinting of the mouse insulin-like growth factor II gene. Cell 64:849-859

5. Haig D, Graham C 1991 Genomic imprinting and the strange case of the insulin-like growth factor II receptor. Cell 64:1045-1046

6. Constancia M, Hemberger M, Hughes J, Dean W, Ferguson-Smith A, Fundele R, Stewart F, Kelsey G, Fowden A, Sibley C, Reik W 2002 Placental-specific IGF-II is a major modulator of placental and fetal growth. Nature 417:945-948

7. Hedborg F, Holmgren L, Sandstedt B, Ohlsson R 1994 The cell type-specific IGF2 expression during early human development correlates to the pattern of overgrowth and neoplasia in the Beckwith-Wiedemann syndrome. Am J Pathol 145:802-817

8. Hafner E, Schuchter K, Metzenbauer M, Phillipp K 2000 Uterine artery Doppler perfusion in the first and second pregnancies. Ultrasound Obstet Gynecol 16:625-629

9. Naeye RL 1983 Maternal age, obstetric complications, and the outcome of pregnancy. Obstet Gynecol 61:210-216

10. Wallace J, Bourke D, Da Silva P, Aitken R 2001 Nutrient partitioning during adolescent pregnancy. Reproduction 122:347-357

11. Barker DJ, Osmond C 1988 Low birth weight and hypertension. BMJ 297:134-135

12. Barker DJ, Winter PD, Osmond C, Margetts B, Simmonds SJ 1989 Weight in infancy and death from ischaemic heart disease. Lancet 2:577-580

13. Barker DJ 1998 Mothers, Babies and Health in Later Life. Churchill Livingstone, Edinburgh, pp 1-217

14. Eriksson JG, Forsen T, Tuomilehto J, Winter PD, Osmond C, Barker DJ 1999 Catch-up growth in childhood and death from coronary heart disease: longitudinal study. BMJ 318:427-431

15. Hales CN, Barker DJ 2001 The thrifty phenotype hypothesis. Br Med Bull 60:5-20

16. Neel JV 1999 The "thrifty genotype" in 1998. Nutr Rev 57:S2-S9

17. Lucas A 1991 Programming by early nutrition in man. In: Bock GR, Whelan J (eds) The Childhood Environment, and Adult Disease. John Wiley, Chichester, pp 38-55

18. Osmond C, Barker DJP 2000 Fetal, infant, and childhood growth are predictors of coronary heart disease, diabetes, and hypertension in adult men and women. Environ Health Perspect 108:545-553

19. Eriksson JG, Lindi V, Uusitupa M, Forsen TJ, Laakso M, Osmond C, Barker DJ 2002 The effects of the Pro12Ala polymorphism of the peroxisome proliferator-activated receptor- $\gamma 2$ gene on insulin sensitivity and insulin metabolism interact with size at birth. Diabetes 51:2321-2324

20. Kemp M, Gunnell D, Maynard M, Smith GD, Frankel S 2000 How accurate is self reported birth weight among the elderly? J Epidemiol Community Health 54:639

21. Huxley R, Neil A, Collins R 2002 Unravelling the fetal origins hypothesis: is there really an inverse association between birthweight and subsequent blood pressure? Lancet 360:659-665

22. Cutfield WS, Hofman PL, Vickers M, Breier B, Blum WF, Robinson EM 2002 IGFs and binding proteins in short children with intrauterine growth retardation. J Clin Endocrinol Metab 87:235-239

23. Hofman PL, Cutfield WS, Robinson EM, Bergman RN, Menon RK, Sperling MA, Gluckman PD 1997 Insulin resistance in short children with intrauterine growth retardation. J Clin Endocrinol Metab 82:402-406

24. Ravelli GP, Stein ZA, Susser MW 1976 Obesity in young men after famine exposure in utero and early infancy. N Engl J Med 295:349-353

25. Ravelli AC, van der Meulen JH, Osmond C, Barker DJ, Bleker OP 1999 Obesity at the age of $50 \mathrm{y}$ in men and women exposed to famine prenatally. Am J Clin Nutr 70:811-816 
26. Godfrey K, Robinson S, Barker DJ, Osmond C, Cox V 1996 Maternal nutrition in early and late pregnancy in relation to placental and fetal growth. BMJ 312:410-414

27. Oliver MH, Breier BH, Gluckman PD, Harding JE 2002 Birth weight rather than maternal nutrition influences glucose tolerance, blood pressure and IGF-1 levels in sheep. Pediatr Res 52:516-524

28. Hanson M 2002 Birth weight and the fetal origins of adult disease. Pediatr Res 52:473-474

29. Bertram CE, Hanson MA 2001 Animal models and programming of the metabolic syndrome. Br Med Bull 60:103-121

30. Bertram CE, Hanson MA 2002 Prenatal programming of postnatal endocrine responses by glucocorticoids. Reproduction 124:459-467

31. Hoet JJ, Hanson MA 1999 Intrauterine nutrition: its importance during critical periods for cardiovascular and endocrine development. J Physiol 514:617-627

32. Poulsen P, Vaag AA, Kyvik KO, Moller Jensen D, Beck-Nielsen H 1997 Low birth weight is associated with NIDDM in discordant monozygotic and dizygotic twin pairs. Diabetologia 40:439-446

33. Jefferies C, Hofman PL, Knoblauch H, Luft FC, Robinson EM, Cutfield WC 2004 Insulin resistance in healthy prepubertal twins. J Pediatr 144:608-613

34. Kind KL, Simonetta G, Clifton PM, Robinson JS, Owens JA 2002 Effect of materna feed restriction on blood pressure in the adult guinea pig. Exp Physiol 87:469-477

35. Kwong WY, Wild AE, Roberts P, Willis AC, Fleming TP 2000 Maternal undernutrition during the preimplantation period of rat development causes blastocyst abnormalities and programming of postnatal hypertension. Development 127:4195-4202

36. Wolff GL, Kodell RL, Moore SR, Cooney CA 1998 Maternal epigenetics and methy supplements affect agouti gene expression in $\mathrm{A}^{\mathrm{v} y} / a$ mice. FASEB J 12:949-957

37. Brawley L, Torrens C, Anthony FW, Itoh S, Wheeler T, Jackson AA, Clough GF Poston L, Hanson MA 2003 Glycine rectifies vascular dysfunction induced by dietary protein imbalance during pregnancy. J Physiol 554:497-504

38. Brawley L, Dance CS, Dunn RL, Anthony FA, Wheeler T, Jackson AA, Poston L, Hanson MA 2003 Dietary folate supplementation prevents the attenuated relaxation to vascular endothelial growth factor (VEGF) in the uterine artery of protein-restricted pregnant rats. Pediatr Res $53.37 \mathrm{~A}$

39. Young LE, Fernandes K, McEvoy TG, Butterwith SC, Gutierrez CG, Carolan C, Broadbent PJ, Robinson JJ, Wilmut I, Sinclair KD 2001 Epigenetic change in IGF2R is associated with fetal overgrowth after sheep embryo culture. Nat Genet 27:153-154

40. McCormick JA, Lyons V, Jacobson MD, Noble J, Diorio J, Nyirenda M, Weaver S Ester W, Yau JL, Meaney MJ, Seckl JR, Chapman KE 2000 5'-heterogeneity of glucocorticoid receptor messenger RNA is tissue specific: differential regulation of variant transcripts by early-life events. Mol Endocrinol 14:506-517

41. Lumey LH 1992 Decreased birthweights in infants after maternal in utero exposure to the Dutch famine of 1944-1945. Paediatr Perinat Epidemiol 6:240-253

42. Torrens C, Itoh S, Brawley L, Barker AC, Poston L, Hanson MA 2002125.14 Maternal protein restriction of pregnant rats impairs vasodilatation in their female offspring (\#125.14). FASEB J 16:4:A104

43. Torrens C, Brawley L, Dance CS, Itoh S, Poston L, Hanson MA 2002 First evidence for transgenerational vascular programming in the rat protein restriction model J Physiol 543.P:41P-42P

44. Torrens C, Brawley L, Barker AC, Itoh S, Poston L, Hanson MA 2002 Materna protein restriction in the rat impairs resistance artery but not conduit artery function in the pregnant offspring. J Physiol 547:77-84

45. Ibanez L, Potau N, Enriquez G, de Zegher F 2000 Reduced uterine and ovarian size in adolescent girls born small for gestational age. Pediatr Res 47:575-577

46. Petrik J, Reusens B, Arany E, Remacle C, Coelho C, Hoet JJ, Hill DJ 1999 A low protein diet alters the balance of islet cell replication and apoptosis in the fetal and neonatal rat and is associated with a reduced pancreatic expression of insulin-like growth factor-II. Endocrinology 140:4861-4873

47. Mallard C, Loeliger M, Copolov D, Rees S 2000 Reduced number of neurons in the hippocampus and the cerebellum in the postnatal guinea-pig following intrauterine growth-restriction. Neuroscience 100:327-333

48. Jennings BJ, Ozanne SE, Dorling MW, Hales CN 1999 Early growth determines longevity in male rats and may be related to telomere shortening in the kidney. FEBS Lett 448:4-8

49. Brawley L, Poston L, Hanson MA 2003 Mechanisms underlying the programming of small artery dysfunction: review of the model using low protein diet in pregnancy in the rat. Arch Physiol Biochem 111:25-35

50. Leeson CP, Kattenhorn M, Morley R, Lucas A, Deanfield JE 2001 Impact of low birth weight and cardiovascular risk factors on endothelial function in early adult life. Circulation 103:1264-1268

51. Wintour EM, Moritz KM, Johnson K, Ricardo S, Samuel CS, Dodic M 2003 Reduced nephron number in adult sheep, hypertensive as a result of prenatal glucocorticoid treatment. J Physiol 549:929-935

52. Keller G, Zimmer G, Mall G, Ritz E, Amann K 2003 Nephron number in patients with primary hypertension. N Engl J Med 348:101-108
53. Ingelfinger JR 2003 Is microanatomy destiny? N Engl J Med 348:99-100

54. Mackenzie HS, Brenner BM 1995 Fewer nephrons at birth: a missing link in the etiology of essential hypertension? Am J Kidney Dis 26:91-98

55. Greenwood PL, Hunt AS, Hermanson JW, Bell AW 2000 Effects of birth weight and postnatal nutrition on neonatal sheep: II. Skeletal muscle growth and development. J Anim Sci 78:50-61

56. Burns SP, Desai M, Cohen RD, Hales CN, Iles RA, Going TC, Bailey RA 1997 Gluconeogenesis, glucose handling, and structural changes in livers of the adult offspring of rats partially deprived of protein during pregnancy and lactation. J Clin Invest 100:1768-1774

57. Hawkins P, Hanson MA, Matthews SG 2001 Maternal undernutrition in early gestation alters molecular regulation of the hypothalamic-pituitary-adrenal axis in the ovine fetus. J Neuroendocrinol 13:855-861

58. Vickers MH, Breier BH, Cutfield WS, Hofman PL, Gluckman PD 2000 Fetal origins of hyperphagia, obesity and hypertension and its postnatal amplification by hypercaloric nutrition. Am J Physiol Endocrinol Metab 279:E83-E87

59. Vickers M, Breier B, McCarthy D, Gluckman P 2003 Sedentary behavior during postnatal life is determined by the prenatal environment and exacerbated by postnatal hypercaloric nutrition. Am J Physiol Intergr Comp Physiol 285:R271-R273

60. Ong KK, Ahmed ML, Emmett PM, Preece MA, Dunger DB 2000 Association between postnatal catch-up growth and obesity in childhood: prospective cohort study. BMJ 320:967-971

61. Bauman DE, Currie WB 1980 Partitioning of nutrients during pregnancy and lactation: a review of mechanisms involving homeostasis and homeorhesis. J Dairy Sci 63:1514-1529

62. Gluckman PD, Hanson MA 2004 The Fetal Matrix: Evolution, Development, and Disease. Cambridge University Press, Cambridge (in press)

63. Lee TM, Zucker I 1988 Vole infant development is influenced perinatally by maternal photoperiodic history. Am J Physiol 255:R831-R838

64. Lee TM, Spears N, Tuthill CR, Zucker I 1989 Maternal melatonin treatment influences rates of neonatal development of meadow vole pups. Biol Reprod 40:495-502

65. Metcalfe NB, Monaghan P 2003 Growth versus lifespan: perspectives from evolutionary ecology. Exp Gerontol 38:935-940

66. Cichón M 1997 Evolution of longevity through optimal resource allocation. Proc Royal Soc Lond B 264:1383-1388

67. Morton NE 1955 The inheritance of human birth weight. Ann Hum Genet 20:125134

68. Stettler N, Tershakovec AM, Zemel BS, Leonard MB, Boston RC, Katz SH, Stallings VA 2000 Early risk factors for increased adiposity: a cohort study of African American subjects followed from birth to young adulthood. Am J Clin Nutr 72:378 383

69. Morton SM 2002 Life Course Determinants of Offspring Size at Birth: An Intergenerational Study of Aberdeen Women. University of London, London

70. Yajnik CS, Lubree HG, Rege SS, Naik SS, Deshpande JA, Deshpande SS, Joglekar CV, Yudkin JS 2002 Adiposity and hyperinsulinemia in Indians are present at birth. J Clin Endocrinol Metab 87:5575-5580

71. Yajnik CS, Fall CH, Coyaji KJ, Hirve SS, Rao S, Barker DJ, Joglekar C, Kellingray S 2003 Neonatal anthropometry: the thin-fat Indian baby: the Pune maternal nutrition study. Int J Obes Relat Metab Disord 27:173-180

72. Stanhope JM, Prior IA 1980 The Tokelau island migrant study: prevalence and incidence of diabetes mellitus. N Z Med J 92:417-421

73. Greenwood PL, Hunt AS, Hermanson JW, Bell AW 1998 Effects of birth weight and postnatal nutrition on neonatal sheep: I. Body growth and composition, and some aspects of energetic efficiency. J Anim Sci 76:2354-2367

74. Barker M, Robinson S, Osmond C, Barker DJ 1997 Birth weight and body fat distribution in adolescent girls. Arch Dis Child 77:381-383

75. Jaquet D, Leger J, Tabone MD, Czernichow P, Levy-Marchal C 1999 High serum leptin concentrations during catch-up growth of children born with intrauterine growth retardation. J Clin Endocrinol Metab 84:1949-1953

76. Bavdekar A, Yajnik CS, Fall CH, Bapat S, Pandit AN, Deshpande V, Bhave S, Kellingray SD, Joglekar C 1999 Insulin resistance syndrome in 8-year-old Indian children: small at birth, big at 8 years, or both? Diabetes 48:2422-2429

77. Yajnik CS, Joglekar CV, Pandit AN, Bavdekar AR, Bapat SA, Bhave SA, Leary SD, Fall CHD 2003 Higher offspring birth weight predicts the metabolic syndrome in mothers but not fathers 8 years after delivery: the Pune children's study. Diabetes 52:2090-2096

78. Fall CH, Yajnik CS, Rao S, Davies AA, Brown N, Farrant HJ 2003 Micronutrients and fetal growth. J Nutr 133:1747S-1756S

79. Rao S, Yajnik CS, Kanade A, Fall CH, Margetts BM, Jackson AA, Shier R, Joshi S, Rege S, Lubree H, Desai B 2001 Intake of micronutrient-rich foods in rural Indian mothers is associated with the size of their babies at birth: Pune maternal nutrition study. J Nutr 131:1217-1224

80. Black RE 2001 Micronutrients in pregnancy. Br J Nutr 85:S193-S197 